\title{
Critical reappraisal of anorectal function tests in patients with faecal incontinence who have failed conservative treatment
}

\author{
T. J. Lam • C. J. J. Mulder • R. J. F. Felt-Bersma
}

Accepted: 20 January 2012 / Published online: 18 February 2012

(C) The Author(s) 2012. This article is published with open access at Springerlink.com

\begin{abstract}
Objective Anorectal function tests are often performed in patients with faecal incontinence who have failed conservative treatment. This study was aimed to establish the additive value of performing anorectal function tests in these patients in selecting them for surgery.

Patients and methods Between 2003 and 2009, all referred patients with faecal incontinence were assessed by a questionnaire, anorectal manometry and anal endosonography. Patients with diarrhea, inflammatory bowel disease, pouches or rectal carcinoma were excluded.

Results In total, 218 patients were evaluated. Of these, 107 (49\%) patients had no sphincter defects, 71 (33\%) had small defects and $40(18 \%)$ had large defects. Anorectal manometry could not differentiate between patients with and without sphincter defects. Patients with sphincter defects were only found to have a significantly shorter sphincter length and reduced rectal capacity compared to patients without sphincter defects. Forty-three patients $(20 \%)$ had a normal anal pressures $\geq 40 \mathrm{mmHg}$. Seventeen patients (8\%) had also a dyssynergic pelvic floor both on clinical examination and anorectal manometry. Fifteen patients $(7 \%)$ had a reduced rectal capacity between 65 and $100 \mathrm{ml}$. There was no difference in anal pressures or the presence of sphincter defects in these patients compared to patients with a rectal capacity $>150 \mathrm{ml}$. There was no correlation between anorectal manometry, endosonography and faecal incontinence severity scores. Conclusion In patients with faecal incontinence who have failed conservative treatment, only anal endosonography can reveal sphincter defects. Anorectal manometry should
\end{abstract}

T. J. Lam $(\triangle)$ • C. J. J. Mulder • R. J. F. Felt-Bersma Department of Gastroenterology and Hepatology,

VU University Medical Center,

P.O. Box 7057, 1007 MB, Amsterdam, The Netherlands

e-mail: tj.lam@vumc.nl be reserved for patients eligible for surgery to exclude those with suspected dyssynergic floor or reduced rectal capacity.

Keywords Faecal incontinence - Diagnostic tests · Anorectal manometry $\cdot$ Anal endosonography $\cdot$ Anal sphincter

\section{Introduction}

Faecal incontinence (FI) is a disabling condition with an estimated prevalence of $6 \%$ in the adult population [1]. Causes of FI are disruption of the anal sphincters secondary to obstetric or surgical trauma, neurologic impairment related to nervus pudendus damage due to chronic straining during delivery or chronic constipation, neuropathy such as diabetes mellitus and multiple sclerosis, decreased rectal capacity (RC) secondary to inflammatory bowel disease, radiation proctitis or irritable bowel syndrome (IBS), diarrhea, reduced mental awareness and the physical inability to reach toilet facilities.

Treatment options for FI are limited. The first step in the management of patients with FI is often dietary modification with fibre and physiotherapy or biofeedback [2-4]. The efficacy of these therapies varies from $50 \%$ and $70 \%$ for dietary fibre and biofeedback, respectively [5-7]. In patients who are refractory to conservative treatment, surgical intervention aimed at correcting a diagnosed sphincter defect, would be the next approach. Other surgical techniques such as sacral nerve stimulation (SNS), gracilis plasty and artificial bowel sphincter creation may be offered to selected patients and are only performed in limited centers $[8,9]$.

Anal endosonography and MRI are considered as valuable tools for demonstrating the integrity of the anal sphincters and consequently play a key role in helping to select patients for surgical repair $[10,11]$. The sensitivity and specificity of anal endosonography reach almost $100 \%$ in identifying anal 
sphincter defects [12, 13]. Moreover, the reproducibility for sphincter defects and anal sphincter thickness is excellent [14]. Furthermore, the presence of atrophy of the sphincters can be established $[15,16]$.

Anorectal manometry is used to measure the anal pressures objectively and to determine the RC. Anal manometry can demonstrate lower sphincter pressures in patients with anal sphincter defects, but also in patients with atrophy and is not discriminatory $[15,16]$. Anal manometry cannot predict the efficacy of physiotherapy and biofeedback [17].

Considering these diagnostic and therapeutic options, the key question is which tests influence clinical decision making. Fibres are a first line, easy to implement, inexpensive treatment and the effect becomes clear after several weeks. Physiotherapy or biofeedback involves more effort from both patient and physiotherapist and is more costly. Anorectal function testing cannot predict the success of physiotherapy or biofeedback [17]. In patients who are eligible for surgery, demonstration of a large sphincter defect is important. Contraindications for sphincter repair are other (concomitant) causes such as diarrhea, severe atrophy of the sphincters, dyssynergic pelvic floor and a very small rectal compliance. Moreover, for other surgical options like SNS, gracilis plasty and artificial bowel sphincter creation, diarrhea, dyssynergic pelvic floor and a small rectal compliance are contraindications.

Although it is well known that anorectal manometry cannot identify anal sphincter defects, it is still routinely performed and many investigators believe it is important or equally important as anal endosonography and contributes greatly to its test results. The aims of this study were to evaluate whether the addition of anorectal manometry to anal endosonography provided additional information to guide the surgical management of patients with FI who have failed conservative treatment and to establish clear recommendations for the targeted use of these tests.

\section{Materials and methods}

\section{Study population}

All consecutive patients referred for the evaluation of FI to our function laboratory between 2003 and 2009 were included. They were prospectively assessed by a comprehensive questionnaire regarding their perianal complaints, including the duration of symptoms, frequency of bowel movements, stool consistency and the use of pads. Other lines of enquiry included the presence of urinary incontinence, the use of medications and the social impact of FI on their lifestyle. Furthermore, a comprehensive past obstetric, surgical, and drug history was taken. The severity of incontinence was graded using the Vaizey and Wexner scores $[18,19]$.
Patients with inflammatory bowel disease, proctitis, pouches or rectal and prostate carcinomas were excluded. Since diarrhea by itself can cause FI, patients with chronic diarrhea were also excluded. Diarrhea was considered as a stool frequency of more than three times a day and the loss of liquid stools. For the consistency of the stool, a nominal scale (liquid, soft, solid and variable) was used.

We classified the patients into three groups: (1) those without anal sphincter defects; (2) those with small sphincter defects; and (3) those with large sphincter defects. A defect comprised at least 30 degrees of the circumference of the sphincter. A sphincter defect was considered small if the circumference was less than $25 \%$ and large if it was more than $25 \%$.

\section{Anorectal manometry}

A four-microtip transducer, water-perfused catheter (Mui Scientific Type SR4B-5-0-0-0, Mississauga, Ontario, Canada) was used. The water-perfusion method was performed by means of a pull-through technique. With the patient lying in the left lateral position, the catheter was introduced into the rectum. After introduction into the rectum, the catheter was withdrawn with the automatic puller at a speed of $1 \mathrm{~mm} / \mathrm{s}$. The maximum basal pressure (MBP) was measured as the mean of highest pressure in rest (normal $40-80 \mathrm{mmHg}$ ). The sphincter length (SL) was equivalent to the length over which the MBP was measured. The maximum squeeze pressure (MSP) was measured as the mean increase of pressure from basal pressure during squeezing (normal $\geq 40 \mathrm{mmHg}$ ). The patient was then asked to strain on three separate occasions. No relaxation on straining was defined as a lack of pressure fall in the anal canal on straining under three consecutive attempts. Paradoxical contraction was defined as an increase of anal basal pressure upon straining.

The rectoanal inhibitory reflex (RAIR) was elicited by inflating the rectal balloon to a position where the MBP was at its highest. The volume necessary for the inhibition and recovery of the MBP was recorded.

The rectal compliance was determined with the rectal balloon. Air was inflated manually sing a syringe at a speed of $60 \mathrm{ml}$ in $15 \mathrm{~s}$. The volume of air needed to be inserted to illicit the first sensation of rectal distension, the urge to defecate and the onset of intolerable distension, which is similar to RC, was measured.

Anal endosonography

Anal endosonography was performed using a threedimensional diagnostic ultrasound system (Hawk type 2050; B-K Medical, Naerum, Denmark) with a rotating 
endoprobe with two crystals, covering $2-16 \mathrm{MHz}$ (focal range $2-4.5 \mathrm{~cm}$ ) (diameter $1.7 \mathrm{~cm}$ ), producing a $360^{\circ}$ view. During recording, the crystals were automatically pulled back by an internal puller, allowing longitudinal distances to be measured. After the endosonography, images were reconstructed into 3D images using computer software. Further details of the methodology of anal endosonography have been previously published [20]. The aspect of the puborectal muscle, external anal sphincter (ESD), internal anal sphincter and submucosa were described. Defects in the ESD were described as hypoechogenic lesions and the extent of the defect was axially measured in hours. The 12 o'clock position was designated as anterior and the 3 o'clock position as left lateral. The 3 o'clock position was located at 90 degrees rotating clockwise. The length of the defect was indicated as proximal, distal or total. Internal anal sphincter defects (ISD) were described as disruption or irregularity of the hypo-echogenic ring. Atrophy of the EAS was judged upon its reflection of the outer interface (border ESD and sub-adventitial fat), reflection pattern and length [21].

\section{Statistical analysis}

Fisher's exact test and Pearson chi-square test were used to compare proportions where appropriate. Student's $t$ test was used to compare continuous data. Spearman correlation coefficients were used to determine relationships between the anal pressures and the Vaizey score and Wexner score. All $P$ values were two-tailed and statistical significance was taken as a $P$ value of less than 0.05. Analyses were performed with the statistical software SPSS version 15.0.

\section{Results}

\section{Clinical features}

In total, 626 patients underwent anorectal function evaluation. Of them, 218 patients met the inclusion criteria for FI and were included in the study (Table 1). Ten patients $(5 \%)$ were men. Of the remaining 208 female patients, $192(92 \%)$ had at least one previous vaginal delivery (mean 2.2, range $0-9$ ). The mean duration of FI was 4.9 years.

\section{Anorectal manometry}

\section{Anal pressures}

Male patients had a higher MSP ( 39 vs. $28 \mathrm{mmHg} ; P=0.03$ ) and longer SL ( 3.6 vs. $3.0 \mathrm{~cm} ; P=0.04$ ) than female patients
Table 1 Demographic and anorectal manometry measurements of the patients with and without sphincter defects on anal endosonography

\begin{tabular}{|c|c|c|c|}
\hline & $\begin{array}{l}\text { Patients with } \\
\text { no defects, } \\
n=107(49 \%)\end{array}$ & $\begin{array}{l}\text { Patients with } \\
\text { small defects, } \\
n=71(33 \%)\end{array}$ & $\begin{array}{l}\text { Patients with } \\
\text { large defects, } \\
n=40(18 \%)\end{array}$ \\
\hline Age (years) & $63(33-90)^{9 \mid}$ & $57(31-83)^{\pi}$ & $49(21-73)^{ \pm}$ \\
\hline Female (\%) & $98(92 \%)$ & $70(99 \%)$ & $40(100 \%)$ \\
\hline \multicolumn{4}{|l|}{ Medical history } \\
\hline Diabetes mellitus (\%) & $6(6)$ & $3(4)$ & $1(3)$ \\
\hline Multiple sclerosis (\%) & $4(4)$ & 0 & 0 \\
\hline Parkinson's disease (\%) & $1(1)$ & $1(1)$ & 0 \\
\hline Vascular problems (\%) & $5(5)$ & 0 & 0 \\
\hline \multicolumn{4}{|l|}{ Surgical history } \\
\hline No surgical history (\%) & $38(36)^{\$} \#$ & $11(15)^{\#}$ & $0^{\$}$ \\
\hline Colorectal/anal (\%) & $15(15)$ & $8(11)$ & $11(28)$ \\
\hline Urogenital (\%) & $53(49)$ & $53(74)$ & $29(73)$ \\
\hline Other $^{\mathrm{a}}(\%)$ & $1(1)$ & 0 & 0 \\
\hline \multicolumn{4}{|l|}{ Anorectal manometry } \\
\hline MBP (mmHg) & $40(10-80)^{\wedge}$ & $37(10-70)$ & $35(10-65)^{\wedge}$ \\
\hline MSP (mmHg) & $30(5-80)$ & $28(5-60)$ & $28(10-80)$ \\
\hline $\mathrm{SL}(\mathrm{cm})$ & $3.1(1-6)^{\%}$ & $3.0(1-5)$ & $2.8(1-4)^{\%}$ \\
\hline \multicolumn{4}{|l|}{ Relaxation } \\
\hline Yes $(\%)$ & $98(93)$ & $63(89)$ & $37(97)$ \\
\hline No $(\%)$ & $6(6)$ & $5(7)$ & 0 \\
\hline Paradox (\%) & $2(2)$ & $3(4)$ & $1(3)$ \\
\hline \multicolumn{4}{|l|}{ RAIR } \\
\hline Yes $(\%)$ & $105(98)$ & $69(97)$ & $40(100)$ \\
\hline No $(\%)$ & $2(2)$ & $2(3)$ & 0 \\
\hline FS (ml) & $82(15-300)$ & $66(10-240)$ & $66(15-200)$ \\
\hline Urge (ml) & $142(35-300)$ & $116(30-250)$ & $117(50-240)$ \\
\hline $\mathrm{RC}(\mathrm{ml})$ & $209(70-350)^{* \&}$ & $172(65-300)^{*}$ & $172(90-350)^{\&}$ \\
\hline
\end{tabular}

Small defect $<25 \%$ circumference

Large defect $>25 \%$ circumference

$M B P$ maximum basal pressure, $M S P$ maximum squeeze pressure, $S L$ sphincter length, RAIR rectoanal inhibitory reflex, FS first sensation, $R C$ rectal capacity

${ }^{a}$ Other: surgery for lumbar disc herniation

" $P=0.001$

${ }^{£} P<0.001$

${ }^{\$} P<0.001$

${ }^{\#} P=0.004$

${ }^{\wedge} P=0.09$

${ }^{\%} P=0.07$

$* P<0.001$

${ }^{\&} P=0.006$

(Table 1). Forty-three (20\%) patients had normal pressures (MBP and MSP $\geq 40 \mathrm{mmHg}$ ). Fifty (23\%) and ten (5\%) patients had low pressures and very low pressures (MBP and MSP $<40$ and $<20 \mathrm{mmHg}$, respectively). Nine patients (8\%) could not relax their pelvic floors properly on clinical examination and manometry. 


\section{Rectal compliance}

Fifteen patients (7\%) had an RC between 65 and $100 \mathrm{ml}$. These patients did not differ from patients with an RC $>100$ or patients with an $\mathrm{RC}>150 \mathrm{ml}$ with regard to anal pressures and the presence of sphincter defects. There was no difference in RC between patients with normal and (very) low pressures. When analyzing $\mathrm{RC}$ parameters for male and female patients separately, the results remained the same.

\section{Anal endosonography}

The frequency and type of sphincter defects are presented in Table 2. Patients without sphincter defects were older, had less previous surgery and had a larger RC in comparison to patients with an anal sphincter defect. Furthermore, patients with large defects tended to have a lower MBP (35 vs. $40 \mathrm{mmHg} ; P=0.09)$ and a shorter SL ( 2.8 vs. $3.1 \mathrm{~cm} ; P=0.07)$ compared to patients without sphincter defects. Four patients with large sphincter defects had an $\mathrm{RC} \leq 100 \mathrm{ml}$. No differences were found in anal manometry findings between patients with small and large defects as well as patients with an ESD and combined ISD and ESD.

Patients with atrophy had a lower MBP (34 vs. $39 \mathrm{mmHg}$; $P=0.04)$ and a lower MSP ( 23 vs. $30 \mathrm{mmHg} ; P=0.001$ ) compared to patients without atrophy. In the group of patients without defects, patients with atrophy had a lower MBP (35 vs. $43 \mathrm{mmHg} ; P=0.01$ ) and a lower MSP (24 vs. $32 \mathrm{mmHg} ; P=0.004$ ) compared to patients without atrophy.

Faecal incontinence scores

The mean Vaizey score and the Wexner score were 15 (range 6-22) and 13 (range 6-20), respectively. The Vaizey score did not correlate with the MBP, the MSP or the RC. Similar findings were found for the Wexner score. However, when the population was subdivided with respect to the stool consistency, a correlation was found between the Vaizey score and the MBP and MSP in patients with soft stool $(r=-0.27, P=0.01$ and $r=-0.23, P=0.03$, respectively). Regarding the Wexner score, a significant correlation was found with the MSP in patients with soft stool $(\mathrm{r}=-0.27$,
$P=0.01)$. No correlation was found between FI scores and sphincter defects.

\section{Discussion}

After therapeutic failure of dietary fibre and physiotherapy, referral and subsequent investigation of patients with FI generally follows. For the detection of anal sphincter defects, anal endosonography (or MRI) is mandatory and considered as the gold standard. Our study has confirmed that anal manometry has no contribution in detecting anorectal sphincter defects. Although patients with large defects tended to have lower MBP $(P=0.09)$ and shorter SL $(P=0.07)$ than patients without sphincter defects, anorectal manometry could not differentiate between patients with and without defects. Other studies have shown comparable results $[13,22]$. Anorectal manometry reflects the anal pressures; low pressures are caused by anal sphincter defects, pudendal neuropathy or both.

A novel anorectal manometry technique, the anal pressure vectography has been developed. It evaluates the radial pressures from a quantified vector symmetry index (VSI) that indicates the anatomical integrity of the anal sphincter. A recent study showed that the VSI was as sensitive as anal endosonography in diagnosing an anal sphincter defect [23]. However, the low pressures measured by VSI cannot differentiate between internal and external sphincter defects and the position of the catheter in the patient is crucial. In contrast with anal endosonography, the internal and external sphincter can be clearly visualized and the location of the sphincter defects is directly related to other anatomical structures. Furthermore, anal endosonography is less time consuming and easier to perform than vectography. Although VSI can produce interesting data for research purposes, it has no place in the work-up of the patient with FI. Anal endosonography is preferable considering the costs and availability.

If anorectal manometry is not useful in the next step of detecting sphincter defects, then what is its contribution in patients who are eligible for surgery? Exclusion of patients with functional abnormalities, such as IBS patients with a small RC or patients with a dyssynergic pelvic floor, seems
Table 2 Findings of anal endosonography ISD internal sphincter defect, $n / a$ not applicable

\begin{tabular}{llcc}
\hline & $\begin{array}{l}\text { Patients with no defects } \\
(n=107)\end{array}$ & $\begin{array}{l}\text { Patients with small } \\
\text { defects }(n=71)\end{array}$ & $\begin{array}{l}\text { Patients with large } \\
\text { defects }(n=40)\end{array}$ \\
\hline $\begin{array}{l}\text { Type of sphincter defect } \\
\text { ESD (\%) }\end{array}$ & $\mathrm{n} / \mathrm{a}$ & $66(93 \%)$ & $11(28 \%)$ \\
ISD (\%) & & 0 & 0 \\
Combined ISD and ESD (\%) & $34(32 \%)$ & $5(7 \%)$ & $29(73 \%)$ \\
Sphincter atrophy (\%) & & $7(10 \%)$ & $4(10 \%)$ \\
\hline
\end{tabular}


wise. Attempts to repair, strengthen or replace the anal sphincter are not logical in the presence of a concomitant functional disorder.

Four $(10 \%)$ of the patients with a large sphincter defect, which means that they have an indication for surgery, had an $\mathrm{RC} \leq 100 \mathrm{ml}$. Patients with an $\mathrm{RC}$ of less than $100 \mathrm{ml}$ are at risk for FI and patients with an RC of less than $60 \mathrm{ml}$ are all incontinent, even in the presence of normal sphincter pressures [24]. In the absence of proctitis, pouches and previous anorectal surgery, IBS is the cause of a relatively low RC.
Therefore, RC measurement is important to exclude IBS with a small RC in patients with FI before surgical intervention.

Some patients have a dyssynergic pelvic floor and therefore have a disturbed coordination of their sphincters. These patients are unable to contract their pelvic floors when faeces arrive and some patients consequently become faecally incontinent. In 17 patients ( $8 \%$ ), we found a non-relaxing pelvic floor, both on clinical examination and anorectal manometry. Anal manometry can be used to confirm the finding of a hypertonic pelvic floor with clinical examination. Clinical

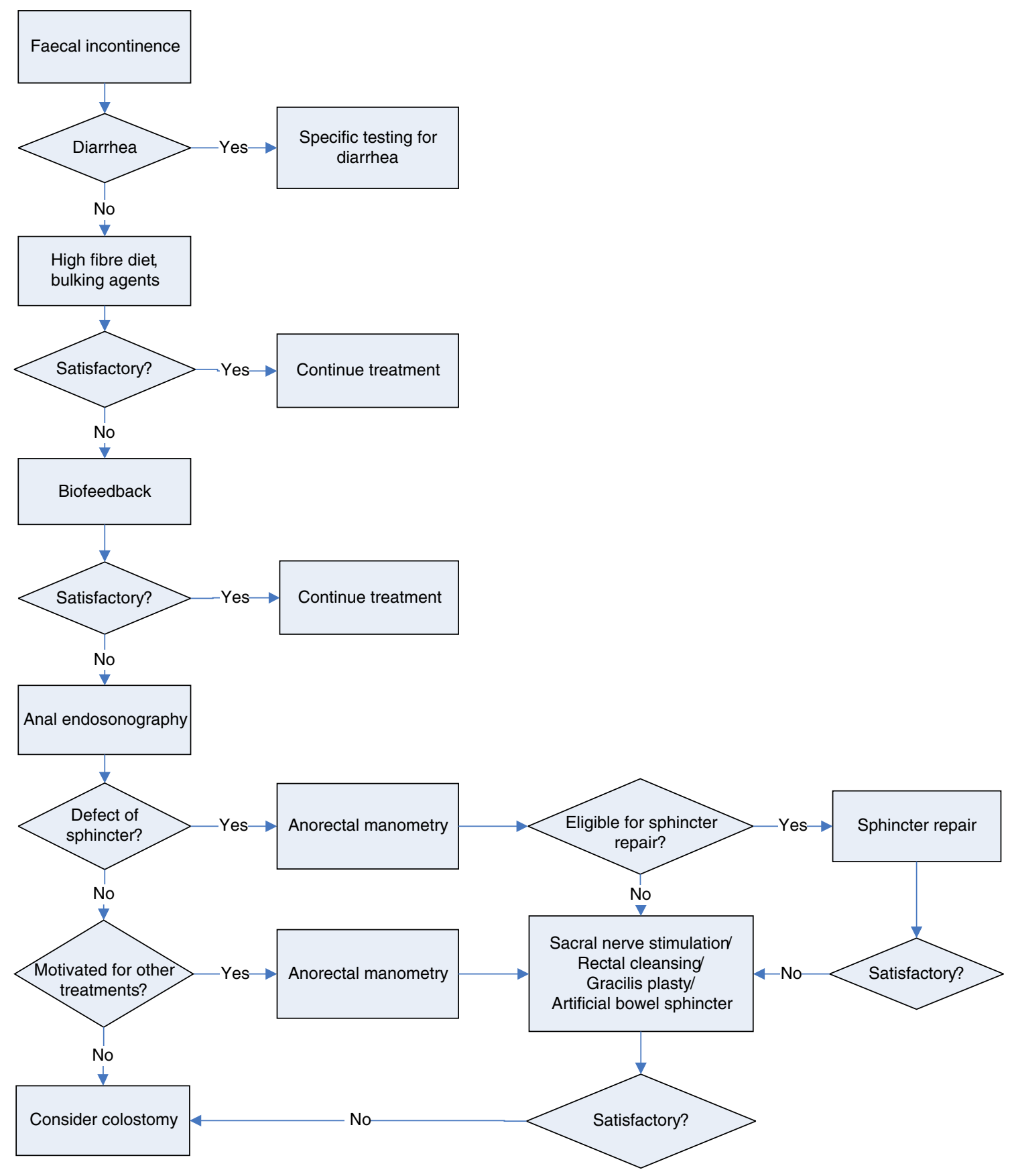

Fig. 1 Flow chart of evaluation of patients with faecal incontinence 
examination by an experienced investigator is just as valuable as anorectal manometry [25] and therefore anorectal manometry for this indication is not necessary. Furthermore, we found in patients with atrophy a lower anal pressure, which conforms with other studies [26, 27].

Does anal manometry have a predictive value with regard to the outcome of sphincter repair or other surgical modalities? The present study showed that anorectal manometry and anal endosonography findings do not correlate well with FI scores. We found a weak correlation between the Vaizey score and the MBP and the Vaizey score and MSP in patients with soft stools. In other recent studies, there was no correlation between the severity of FI and anorectal manometry results observed [28-30]. These findings again underscore the multi-factorial etiology of FI. Since there is no correlation with the severity of FI, little or no predictive value of anorectal manometry in the efficacy of the treatment for FI can be expected [29, 31].

An algorithm for the treatment of FI is given in Fig. 1. Assessment should begin with a thorough clinical work-up. A detailed medical history and clinical examination with a rectal examination are mandatory. In general, the etiology of FI becomes obvious. Patients with diarrhea or proctitis need further evaluation and targeted treatment. Following this, conservative measures (fibres, physiotherapy) should be applied. In the event of treatment failure, the patient should undergo anal endosonography to demonstrate or exclude a large sphincter defect. In cases of doubt, notwithstanding, patients who are eligible for surgical repair should be evaluated by anorectal manometry, which allows an objective measurement of anal pressures, relaxation of the pelvic floor and RC. Patients who are motivated for other treatments such as SNS, gracilis plasty or artificial bowel sphincter creation, also need be fully evaluated pre-operatively $[8,9$, $32,33]$. When all therapies fail, colostomy can be an option.

In conclusion, the present study confirms the importance of anal endosonography in revealing anal sphincter defects and consequently in selecting patients for surgical repair. Although anorectal manometry can provide additional information, it should not be performed routinely in every patient who has failed conservative treatment for FI. Anorectal manometry should be performed in patients selected for surgical intervention to exclude functional abnormalities like dyssynergic floor or IBS with a small RC. In the current adverse economic climate where healthcare budgets are constrained, it is important to reserve the use of tools such as anorectal manometry for those who may benefit from it.

Acknowledgement We thank Dr. Anna Dahele for her critical review and language correction.

\section{Conflict of interest None.}

Open Access This article is distributed under the terms of the Creative Commons Attribution License which permits any use, distribution, and reproduction in any medium, provided the original author(s) and the source are credited.

\section{References}

1. Bartolo DC, Paterson HM (2009) Anal incontinence. Best Pract Res Clin Gastroenterol 23(4):505-515

2. Bharucha AE, Wald AM (2010) Anorectal disorders. Am J Gastroenterol 105(4):786-794

3. Heymen S, Scarlett Y, Jones K et al (2009) Randomized controlled trial shows biofeedback to be superior to pelvic floor exercises for fecal incontinence. Dis Colon Rectum 52(10):1730-1737

4. Ozturk R, Niazi S, Stessman M, Rao SS (2004) Long-term outcome and objective changes of anorectal function after biofeedback therapy for faecal incontinence. Aliment Pharmacol Ther 20 (6):667-674

5. Bliss DZ, Jung HJ, Savik K et al (2001) Supplementation with dietary fiber improves fecal incontinence. Nurs Res 50(4):203-213

6. Heymen S, Jones KR, Ringel Y, Scarlett Y, Whitehead WE (2001) Biofeedback treatment of fecal incontinence: a critical review. Dis Colon Rectum 44(5):728-736

7. Lee BH, Kim N, Kang SB et al (2010) The long-term clinical efficacy of biofeedback therapy for patients with constipation or fecal incontinence. J Neurogastroenterol Motil 16(2):177-185

8. Brown SR, Nelson RL (2007) Surgery for faecal incontinence in adults. Cochrane Database Syst Rev (2):CD001757

9. Wexner SD, Coller JA, Devroede G et al (2010) Sacral nerve stimulation for fecal incontinence: results of a 120-patient prospective multicenter study. Ann Surg 251(3):441-449

10. Felt-Bersma RJ, Cuesta MA, Koorevaar M et al (1992) Anal endosonography: relationship with anal manometry and neurophysiologic tests. Dis Colon Rectum 35(10):944-949

11. Dobben AC, Terra MP, Slors JF et al (2007) External anal sphincter defects in patients with fecal incontinence: comparison of endoanal MR imaging and endoanal US. Radiology 242(2):463471

12. Meyenberger C, Bertschinger P, Zala GF, Buchmann P (1996) Anal sphincter defects in fecal incontinence: correlation between endosonography and surgery. Endoscopy 28(2):217-224

13. Sultan AH, Kamm MA, Talbot IC, Nicholls RJ, Bartram CI (1994) Anal endosonography for identifying external sphincter defects confirmed histologically. Br J Surg 81(3):463-465

14. Felt-Bersma RJ (2008) Endoanal ultrasound in benign anorectal disorders: clinical relevance and possibilities. Expert Rev Gastroenterol Hepatol 2(4):587-606

15. Pinsk I, Brown J, Phang PT (2009) Assessment of sonographic quality of anal sphincter muscles in patients with faecal incontinence. Colorectal Dis 11(9):933-940

16. Reddymasu SC, Singh S, Waheed S et al (2009) Comparison of anorectal manometry to endoanal ultrasound in the evaluation of fecal incontinence. Am J Med Sci 337(5):336-339

17. Terra MP, Deutekom M, Dobben AC et al (2008) Can the outcome of pelvic-floor rehabilitation in patients with fecal incontinence be predicted? Int J Colorectal Dis 23(5):503-511

18. Vaizey CJ, Carapeti E, Cahill JA, Kamm MA (1999) Prospective comparison of faecal incontinence grading systems. Gut 44(1):77-80

19. Wexner SD, Jorge JM (1994) Colorectal physiological tests: use or abuse of technology? Eur J Surg 160(3):167-174

20. Poen AC, de Brauw M, Felt-Bersma RJ, de Jong J, Cuesta MA (1996) Laparoscopic rectopexy for complete rectal prolapse. Clinical outcome and anorectal function tests Surg Endosc 10(9):904-908 
21. Cazemier M, Terra MP, Stoker J et al (2006) Atrophy and defects detection of the external anal sphincter: comparison between threedimensional anal endosonography and endoanal magnetic resonance imaging. Dis Colon Rectum 49(1):20-27

22. Sentovich SM, Blatchford GJ, Rivela LJ et al (1997) Diagnosing anal sphincter injury with transanal ultrasound and manometry. Dis Colon Rectum 40(12):1430-1434

23. Samarasekera DN, Wright Y, Lowndes RH et al (2008) Comparison of vector symmetry index and endoanal ultrasonography in the diagnosis of anal sphincter disruption. Tech Coloproctol 12(3):211-215

24. Felt-Bersma RJ, Sloots CE, Poen AC, Cuesta MA, Meuwissen SG (2000) Rectal compliance as a routine measurement: extreme volumes have direct clinical impact and normal volumes exclude rectum as a problem. Dis Colon Rectum 43(12):1732-1738

25. Tantiphlachiva K, Rao P, Attaluri A, Rao SS (2010) Digital rectal examination is a useful tool for indentifying patients with dyssynergia. Clin Gastroenterol Hepatol 8(11):955-960

26. Terra MP, Deutekom M, Beets-Tan RG et al (2006) Relationship between external anal sphincter atrophy at endoanal magnetic resonance imaging and clinical, functional, and anatomic characteristics in patients with fecal incontinence. Dis Colon Rectum 49 (5):668-678
27. Williams AB, Bartram CI, Modhwadia D et al (2001) Endocoil magnetic resonance imaging quantification of external anal sphincter atrophy. Br J Surg 88(6):853-859

28. Titi MA, Jenkins JT, Urie A, Molloy RG (2008) Correlation between anal manometry and endosonography in females with faecal incontinence. Colorectal Dis 10(2):131-137

29. Zutshi M, Salcedo L, Hammel J, Hull T (2009) Anal physiology testing in fecal incontinence: is it of any value? Int J Colorectal Dis 25(2):277-282

30. Wasserberg N, Mazaheri A, Petrone P, Tulchinsky H, Kaufman HS (2010) 3D endoanal ultrasonography of external anal sphincter defects in patients with faecal incontinence: Correlation with symptoms and manometry. Colorectal Dis 13(4):449-453

31. Hill K, Fanning S, Fennerty MB, Faigel DO (2006) Endoanal ultrasound compared to anorectal manometry for the evaluation of fecal incontinence: a study of the effect these tests have on clinical outcome. Dig Dis Sci 51(2):235-240

32. Mowatt G, Glazener C, Jarrett M (2008) Sacral nerve stimulation for fecal incontinence and constipation in adults: a short version Cochrane review. Neurourol Urodyn 27(3):155-161

33. Madoff RD (2004) Surgical treatment options for fecal incontinence. Gastroenterology 126(1 Suppl 1):S48-S54 